\title{
RESEARCH
}

\section{Association between NAPLEX Preparation Program Characteristics and First-Time Pass Rates}

Karen S. Fiano, PharmD, ${ }^{\mathrm{a}}$ Omar Attarabeen, PhD, ${ }^{\mathrm{b}} \mathrm{Jill} \mathrm{M}$. Augustine, PharmD, MPH, PhD, ${ }^{\mathrm{c}}$ Robert D. Beckett, PharmD, ${ }^{\mathrm{d}}$ Carol S. Goldin, PhD, ${ }^{\mathrm{e}}$ Melissa S. Medina, EdD, ${ }^{\mathrm{f}, \mathrm{g}}$ Nina Pavuluri, PhD,${ }^{\mathrm{h}}$ Julie M. Sease, PharmD ${ }^{\mathrm{i}}$

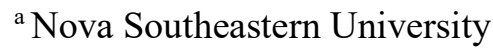

${ }^{\mathrm{b}}$ Marshall University

${ }^{\mathrm{c}}$ Mercer University

${ }^{\mathrm{d}}$ Manchester University

${ }^{\mathrm{e}}$ Rutgers University

${ }^{\mathrm{f}}$ The University of Oklahoma Health Sciences Center

${ }^{g}$ Associate Editor, American Journal of Pharmaceutical Education, Arlington, Virginia

${ }^{\mathrm{h}}$ Lake Erie College of Osteopathic Medicine

${ }^{\mathrm{i}}$ University of South Carolina

Corresponding Author: Karen S. Fiano, Nova Southeastern University, 3200 South University Dr., Office 1374, Davie, FL 33328. Tel: 954-262-4378. Email: karen.fiano@nova.edu

Submitted June 3, 2021; accepted October 15, 2021; ePublished November 2021

Objective. The objectives of this study were to 1) describe characteristics of NAPLEX preparation programs currently utilized by colleges and schools of pharmacy and 2) to evaluate these program characteristics in relation to first-time NAPLEX pass rates.

Methods. This cross-sectional study was based on an online survey administered between February and March 2020. Assessment leads from 143 PharmD programs were invited to answer questions on their schools' PharmD program characteristics and various aspects of NAPLEX preparation programs. The study included regression analyses to investigate the associations between the NAPLEX first-attempt pass rates and PharmD demographic characteristics, as well as data collection on various aspects of the NAPLEX preparation programs. Finally, common themes from the openended questions were identified.

Results. Fifty-eight participants completed the survey out of 132 successfully delivered email invitations (response rate $=$ $44 \%)$. Fifty participants (86\%) indicated that their PharmD program offers a NAPLEX preparation program. Our data indicate that offering a NAPLEX preparation program was not significantly associated with higher NAPLEX first-attempt pass rates. The analysis identified possible explanations for this lack of association, including student concerns with balancing a prep program with APPEs, and faculty workload associated with delivering such programs.

Conclusion. The current findings show no association between offering a NAPLEX preparation program and NAPLEX first attempt pass rate. Future research should continue to examine the impact of these programs on individual school pass rates and factors that may enhance student motivation to engage in these programs.

Keywords: NAPLEX, licensing exam, assessment, NAPLEX preparation, first-time pass rates

\section{INTRODUCTION}

The North American Pharmacist Licensure Examination (NAPLEX), developed and administered by the National Association of Boards of Pharmacy (NABP), is utilized by boards of pharmacy to assess a graduate's competence to practice as a licensed pharmacist. ${ }^{1}$ NAPLEX performance is evaluated as part of the Accreditation Council for Pharmacy Education (ACPE) accreditation standards; mentioned in both Standard 15: Academic Environment and Standard 24: Assessment Elements for Section I: Educational Outcomes as required information for colleges and schools of pharmacy (C/SOP) to assess and provide to students. ${ }^{2}$ In order to fulfill Department of Education requirements, ACPE ensures that each Doctor of Pharmacy program annually posts its most recent first-time pass rate for the NAPLEX to its website for 
public view. As the number of schools of pharmacy has increased since 2000, there is increasing competition for students. NAPLEX passing rates may be an important indicator for prospective students seeking to compare programs.

First-attempt NAPLEX pass rates have recently become a serious concern for colleges and schools of pharmacy, as passing rates began a downward trend in 2014, with the most significant drop occurring between 2015 and 2016 . $^{3,4}$ The NAPLEX competency statements were revised in 2015; in 2016, the exam length was increased from 4.25 hours to 6 hours with an increase from 185 to 250 questions. ${ }^{3}$ At the same time, the model changed from computer-adaptive to preassembled, with set percentages of questions varying in difficulty. The greatest change in the first-attempt pass rate occurred between 2015 and 2016, perhaps corresponding with the changes to the exam, hitting a nadir at $85.86 \% .{ }^{3}$ Since that time, the mean national first-time NAPLEX passing rates have improved $(89.46 \%, 88.34 \%$, and $88.43 \%$ in 2018 , 2019, and 2020, respectively). ${ }^{5}$ NAPLEX competency statements are reviewed every five years to reflect licensure best practices and changes in pharmacy practice. As of January 2021, the blueprint for the NAPLEX has expanded from two competency areas to six, with the largest portion of the exam (35\%) devoted to developing or managing treatment plans. ${ }^{6}$ Short-term fluctuations in pass rates may be anticipated in response to these changes.

Following the decline in nationwide pass rates, there has been considerable interest in identifying characteristics that are associated with students' success on the exam. While early studies focused on individual schools, a study published in 2019 by Williams, et al sought to identify correlations between school characteristics and NAPLEX pass rates, using data from all US C/SOP accredited as of July 2019. ${ }^{3}$ That study concluded that higher first-attempt pass rates were significantly correlated with the C/SOP residing within an academic health center, establishment of the school prior to 2000, public (rather than private) structure, and a 4-year (rather than accelerated 3-year) curriculum. Additionally, there was a positive correlation between percentage of total graduating class that matched for post-graduate year 1 (PGY-1) residencies and NAPLEX passing rates.

A 2017 study by Lebovitz et al reported that approximately $80 \%$ of C/SOPs offer some type of NAPLEX review. ${ }^{7}$ Common descriptions of the review programs included question banks developed by a vendor $(n=45,73.9 \%)$, live reviews provided by a vendor $(n=34,55.7 \%)$, and live reviews provided by local faculty $(n=28,45.9 \%)$. Service to students was the most commonly identified motivator for provision of a review, though private C/SOPs were more likely than public $\mathrm{C} / \mathrm{SOPs}$ to identify poor historical performance on the NAPLEX as motivation $\left(\chi^{2}=8.15, p=.004\right)$. As $\mathrm{C} / \mathrm{SOPs}$ consider whether to use NAPLEX preparation programs, they must evaluate the effectiveness of the program as well as the associated costs, including but not limited to, the costs of the program, faculty salary, and space allocation.

The effectiveness of commercial test preparation has been evaluated in both the medical and pharmacy literature. ${ }^{8-}$

${ }^{12}$ As with pharmacy, some medical schools offer, require, and/or recommend commercial and school-sponsored preparation programs. Several reviews of the impact of preparation programs in medicine indicate no significant differences in United States Medical Licensing Examination (USMLE) Step 1 scores between students who had commercial coaching versus those who prepared on their own. ${ }^{8,9,12}$ Similar results were seen in pharmacy schools, where the use of no one exam preparation tool has been associated with higher examination pass rates, but some products are favored over others by students. ${ }^{11}$

In a study by Zhang et al., which evaluated student perceptions of the preparation methods, students reported that personal learning habits and advice from other medical students were the two most significant factors in successful Step exam preparation. ${ }^{9}$ All students who had participated in a commercial test preparation program indicated that having an organized study schedule was important, while only $59 \%$ of those who did not participate in a formal test preparation program identified the importance of an organized study plan. More surprisingly, participants rated commercial test preparation programs highly, but did not demonstrate higher performance levels. Most students reported that their curriculum prepared them for the exam. Based on an inverse relationship in perceived course quality and perceived quality of the corresponding segment of the preparation course, the authors postulated that participants were attempting to add value to complement content areas they felt were weaker within their curriculum.

A systematic review of previous studies evaluating test preparation is difficult because of limitations in these studies; for example, most did not have control groups. ${ }^{12}$ Selection bias was common since enrolled students were selfselected. Studies did not use prospective randomized controlled trials, provided few details about the commercial educational interventions, and lacked cost-benefit analyses. ${ }^{12}$ Some studies only evaluated student perceptions of perceived utility. ${ }^{12}$ The review also noted a trend in marketing strategies, which focused on student perceptions, rather than the impact of verifiable interventions.

The purpose of the current study is to evaluate, in greater detail, the NAPLEX preparation programs currently utilized by $\mathrm{C} / \mathrm{SOPs}$ and to investigate associations between program characteristics and first-time NAPLEX pass rates. 
Though test preparation programs have been evaluated in relation to the traits of C/SOPs offering them, the specific placement, timing, and structure of those programs have not been fully evaluated in the pharmacy literature to date. The current study seeks to provide details related to program administration and resources so that stakeholders might be better informed about the NAPLEX preparation structure currently utilized by C/SOPs.

\section{METHODS}

This cross-sectional study was based on a self-administered survey as the primary tool for data collection. The survey included highly structured, quantitative as well as qualitative items. Participants were recruited via email invitations that included a link to access the online survey. Qualtrics software (Qualtrics Labs, Provo, Utah) was the platform used for data collection.

The survey consisted of 36 items that were developed based on previous research. ${ }^{3,7-12}$ The survey items measured a series of program characteristics, including the number of graduated classes $(0-5,6-10,11-25,26-50$, and more than 50), the typical number of students in each class $(0-50,51-75,76-100,101-150,151-200$, more than 200), and the accreditation status (pre-candidate, candidate, and fully accredited). Additionally, the survey assessed multiple aspects related to the NAPLEX preparation programs, including development, coordination, implementation timeline, updating, grading, utilization of practice exams, and use of third-party resources such as Exam Master (Exam Master Corp., Newark, DE), Pass NAPLEX Now (Pass NAPLEX Now Inc., Irvine, CA), or RxPrep (Rx Prep, Inc., El Segundo, CA).

The survey was sent to one individual from each of the 143 accredited or candidate PharmD programs in the US with an invitation to take part in the survey. The contacted individuals were identified using a list of program assessment leads, mostly directors or assistant/associate deans for assessment, maintained by the American Association of Colleges of Pharmacy (AACP) Assessment special interest group (SIG). Recipients were asked whether they would suggest an alternative responder from their school if they believed someone else at their program had more extensive knowledge of NAPLEX preparation.

Data collection began in February 2020, and the survey was open for four weeks. Two reminders, approximately one week apart, were sent to individuals who did not complete the survey. Additional reminders were not sent due to the COVID-19 pandemic. After data were collected from the survey, the researchers manually inputted the 2019 NAPLEX first-attempt pass rates published by NABP ${ }^{5}$ for each participating school to evaluate associations between NAPLEX preparation program characteristics and pass rates.

After the basic characteristics of the participating schools were presented, the associations between specific school characteristics and NAPLEX first-attempt pass rates were examined either with point biserial or Spearman's rankorder correlation analyses, as applicable. Then, two linear regression analyses were conducted to investigate the adjusted coefficients and confidence intervals related to the associations between the NAPLEX first-attempt pass rates and selected variables. The first regression analysis examined the association of NAPLEX first-attempt pass rates with offering a NAPLEX preparation program while accounting for program demographic characteristics (school type [public vs. private]; the number of classes the program graduated; the average number of students in each class). The second regression analysis investigated the association of NAPLEX first-attempt pass rates with various aspects of the NAPLEX preparation programs offered by the C/SOPs. Variables included in this analysis were whether the C/SOP required the preparation program for every student, use of the pre-NAPLEX exam, use of a third-party resource, use of a home-grown preparation program, and demographic characteristics of the program as listed above. Variables with substantial missing values or those measured qualitatively were excluded from the regression analyses. Excluding these variables is not expected to impact the results due to the great variability in how the preparation programs are assessed and implemented. Significance was determined at an alpha value of 0.05 . A qualitative analysis of the challenges faced by C/SOP that attempted to implement a NAPLEX preparation program was conducted. The responses were reviewed by two investigators and coded based on themes identified de novo. The codes were compared to ensure consistency and discrepancies were discussed. Frequencies of each code were recorded. The study was designated as exempt from review by the institutional review board (IRB) at Nova Southeastern University

\section{RESULTS}

A total of 143 emails were sent, but 11 were returned as undeliverable. Fifty-eight participants completed the survey out of 132 successfully delivered email invitations (response rate $=44 \%$ ). This response rate represented $41 \%$ of accredited and candidate PharmD programs. The participating programs covered all regions in the US, with largest representation from the Midwest (Table 1). There was similar representation of private and public institutions. Fifty-seven 
programs $(98 \%)$ were fully accredited, with the majority having graduated more than 50 classes. There was good distribution of programs by class size. The mean for the 2019 NABP-published NAPLEX first-attempt pass rates for the participating schools was $88.5 \%$, whereas the median was $91.4 \%$.

Fifty participants $(86 \%)$ indicated that their C/SOP offers a NAPLEX preparation program. Of these, $71 \%$ were required for all students. Fifty-six percent of C/SOPs that offer a NAPLEX preparation program updated their program in response to the changes in the NAPLEX that took effect in 2016. Programs were most often coordinated by academic affairs or assessment-related offices (74\%), experiential education-related offices (39\%), and/or faculty (30\%). Programs took place during the Advanced Pharmacy Practice Experience (APPE) year (80\%), after the APPE's concluded but before graduation (52\%), and/or after graduation (15\%). Forty-eight percent of programs resided within the PharmD curriculum. Student performance was commonly graded (50\% objectively, $20 \%$ subjectively), but $45 \%$ indicated that performance was ungraded or checked only to ascertain completion.

About $33 \%$ of programs reported using the pre-NAPLEX exam with $60 \%$ of programs administering the exam in a proctored setting. About $78 \%$ of the programs used a third-party resource to provide their NAPLEX preparation program; of these, the most common products utilized were RxPrep $(n=30)$ and Exam Master $(n=7)$. Sixty-seven percent of the programs reported administering the third-party resource's practice examination in a proctored setting. At the time of the survey, $46 \%$ of the review courses were delivered in a live format, $26 \%$ blended, $14 \%$ asynchronous, and $14 \%$ other or a combination.

The bivariate association analyses results revealed that the 2019 NAPLEX first-attempt pass rates were significantly lower among C/SOPs that required the NAPLEX preparation program for every student, programs that used a third-party resource (eg, Exam Master, Pass NAPLEX Now , RxPrep ), private C/SOPs, and C/SOPs that graduated fewer classes. More details on the bivariate analyses results are presented in Table 2.

The first linear regression analysis assessed the associations of program demographic characteristics with NAPLEX firstattempt pass rates. Results of this analysis demonstrated that the primary independent variable (offering a NAPLEX preparation program) was not significantly associated with the NAPLEX first-attempt pass rate (Table 3). However, the number of classes that the school graduated was positively associated with it, such that each one-level higher score in the number of graduated classes variable was associated with a $2.36 \%$ increase in NAPLEX first-attempt pass rate. In terms of the measured aspects of the NAPLEX preparation programs, the second linear regression analysis revealed that the number of classes that the PharmD program has graduated continued to be the only significant variable associated with NAPLEX first-attempt pass rates. Each one-level higher score in the number of graduated classes was associated with a $2.37 \%$ increase in NAPLEX first-attempt pass rate. More information about the outcomes of this linear regression is presented in Table 4.

Thirty-eight participants provided a comment on experienced challenges with their NAPLEX preparation program. The most frequent challenge identified was a lack of student motivation in participating and/or completing a preparedness program during APPEs (22 responses) such as students' priority was either on APPEs or they had difficulties devoting dedicated time for a preparation program. The next most frequent challenge ( 7 responses) identified was scheduling: either during APPEs or after completion of APPEs (but before graduation). The final two common themes (each receiving 4 responses) were the perception of whether a program makes a difference and the concern of the time commitment for faculty, staff, and administration for a preparedness program.

\section{DISCUSSION}

Overall, this study found that the number of graduated classes by a C/SOP was the only significant predictor of NAPLEX first-attempt pass rates, while controlling for other program characteristics and characteristics of the NAPLEX preparation program itself. This is the first study to our knowledge that characterizes in detail the NAPLEX preparation programs offered by C/SOP. Responses to the survey indicate the structure, timing, and resources utilized to deliver such programs are variable across the academy. Comments by survey respondents indicated shared struggles in engaging students in these preparation programs while they are busy participating in APPEs.

The number of graduated classes, or in other words, how established a program is, has been correlated with higher NAPLEX pass rates in prior studies. ${ }^{3,7}$ Lebovitz et al found that legacy programs (defined as schools founded before 1995) had significantly higher pass rates than more recently established schools $(93.3 \%$ vs. $90.7 \%, \mathrm{p}=.031) .{ }^{7}$ Williams et al similarly found that NAPLEX pass rates between 2014 and 2016 were significantly higher in schools established before, rather than after, $2000 .{ }^{3}$ In our study, the number of graduated classes was a significant predictor for the NAPLEX pass rate, whether controlling for other characteristics of the NAPLEX preparation program or not. There was a linear 
increase in the number of graduated classes and the NAPLEX pass rates, with an approximate $10 \%$ improvement in firsttime pass rates between schools graduating more than 50 classes (mean pass rate $=91.04 \%$ ) and those graduating 0 to 5 classes (mean pass rate $=81.70 \%$ ). It is unknown why more established programs may have higher NAPLEX pass rates. In this study, we did not have access to student-level admission data, such as GPAs or PCAT scores, so it is difficult to determine if certain programs are recruiting academically stronger students. There also may be some influence of a program's ability to consistently prepare students for success on the NAPLEX, as evidenced by consistently high pass rates across varying years and cohorts. Previous research has shown that a program's prior years NAPLEX pass rates can be a predictor of performance in the following year. ${ }^{3}$

According to our survey, students' lack of motivation to participate in or complete prep programs was the most significant challenge identified by respondents. Previous research on standardized exams (eg, PCOA or NAPEX) has shown that student motivation has been a consistent and major factor in determining performance. ${ }^{13}$ Depending on how a school implements these types of preparation programs, performance may be low stakes, which may lead to diminished intrinsic motivation. The next most frequent challenge was uncertainty about when to schedule a program during the curriculum and/or dedicating time for NAPLEX preparation during APPEs. As seen with PCOA implementation and utilization, ${ }^{14}$ there are a variety of utilization techniques and considerations for these programs. These programs could be curricular or co-curricular; for course credit or not; or required for all students or only poor-performing students. In order to determine the best administration of these programs, faculty should dedicate time, energy, and effort into developing a program that fits with their C/SOP. Given the increased demand on faculty time and the potential for burnout, this may be problematic or not feasible. Finally, there has been limited research published on these programs and their impact on NAPLEX pass rates.

This study has several limitations which must be noted. First, not all C/SOPs responded to the survey so the findings may not be generalizable across all schools. However, respondents were equally distributed between private $(52 \%)$ and public (48\%) schools, which is similar to the national landscape (51\% private; $49 \%$ public). ${ }^{15}$ The majority of respondents to the survey had a class size between 76 and $100(19 \%)$ and 101 to $150(19 \%)$ which is similar to the mean class size of 103 in the Fall 2020 Profile of Pharmacy Students. ${ }^{16}$ The mean NAPLEX first-time pass rate for our sample was $88.5 \%$, which is similar to the $2019(88.3 \%)$ and $2020(88.4 \%)$ national pass rates published by NABP. ${ }^{5}$ While the survey response rate was less than desirable, the results are likely representative of the academy.

There was a wide variety in the type and structure of NAPLEX preparation programs used by each C/SOP, so the intervention was not the same among programs that responded to the survey. However, when performing regression analysis, authors attempted to control for demographic differences among programs that have been shown to impact NAPLEX pass rates (ie, number of graduated classes). This study involved a retrospective review of NAPLEX pass rates so temporal relationships between the use or change of NAPLEX preparation programs and the impact on school pass rates are difficult to determine. Challenges expressed by schools in administering NAPLEX preparation programs are only representative of faculty or administrator opinions and did not capture student's perceptions of these programs. Finally, this study did not collect individual student-level study habits or adherence to the study programs offered by each school. Therefore, we are unable to determine if these factors may have impacted a program's pass rates above and beyond the offer of the program itself.

C/SOPs may consider the results of this study in planning for NAPLEX preparation programs offered at their institutions. Schools should investigate the impact of NAPLEX preparation programs on first-time pass rates at their institution with student-level data regarding the amount and effectiveness of study time associated with them. Programs may use these data in conjunction with other potential predictors of NAPLEX performance (eg, PCOA scores, program GPAs) to determine if student performance within NAPLEX preparation programs may predict NAPLEX pass rates above and beyond existing academic measures. Programs should also evaluate whether all students, or only those at high risk of NAPLEX failure, should receive these resources. Programs should be structured to minimize impact on students during APPEs, while still fostering student intrinsic motivation to study. Involving recent alumni or students in the planning process for these programs may be beneficial to help overcome challenges with deploying such programs during the APPE year and to find ways to help students balance exam preparation with other responsibilities.

\section{CONCLUSION}

Overall, there was no association between offering a NAPLEX preparation program and first-time NAPLEX pass rates. This study identified a wide variety of types and methods of implementation of NAPLEX preparation programs. Established C/SOPs that graduated more than 50 classes showed a significantly higher NAPLEX pass rate. Lack of 
student motivation for active participation in the preparation program was cited as a common concern for delivery of such programs. Future research should explore strategies to enhance student motivation to engage in NAPLEX preparation programs and evaluate the benefits such programs provide to students and colleges/schools of pharmacy.

\section{REFERENCES}

1. The North American Pharmacist Licensure Examination. National Association of Boards of Pharmacy. https://nabp.pharmacy/programs/examinations/naplex/. Accessed June 3, 2021.

2. Accreditation Council for Pharmacy Education. Guidance for the accreditation standards and key elements for the professional program in pharmacy leading to the doctor of pharmacy degree ("Guidance for Standards 2016"). https://www.acpe-accredit.org/pdf/GuidanceforStandards2016FINAL.pdf. Accessed June 3, 2021.

3. Williams JS, Spivey CA, Hagemann TM, Phelps SJ, Chisholm-Burns M. Impact of pharmacy school characteristics on NAPLEX first-time pass rates. Am J Pharm Educ. 2019;83(6):Article 6875.

4. Williams RA. NAPLEX passing rates decline nationwide. Pharmacy Today. 2017;23(5):42. https://www.pharmacytoday.org/article/S1042-0991(17)30605-9/pdf. Accessed June 3, 2021.

5. North American Pharmacist Licensure Examination Passing Rates for 2018-2020 Graduates per Pharmacy School, National Association of Boards of Pharmacy. https:/nabp.pharmacy/wp-content/uploads/2021/03/NAPLEX-Pass-Rates2020.pdf. Accessed June 3, 2021.

6. NAPLEX Competency Statements. National Association of Boards of Pharmacy. https://nabp.pharmacy/programs/examinations/naplex/competency-statements-2021/. Accessed June 3, 2021.

7. Lebovitz L, Shuford VP, DiVall MV, Daugherty KK, and Rudolph MJ. Creating an arms race? Examining school costs and motivation for providing NAPEX and PCOA preparation. Am J Pharm Educ. 2017;81(7):Article 5909.

8. Werner LS and Bull BS. The effect of three commercial coaching courses on Step One USMLE performance. Med Educ. 2003;37:527-531.

9. Zhang C, Rauchwarger A, Toth C, O’Connell M. Student USMLE Step 1 preparation and performance. Adv Heal Sci Educ. 2004;9(4):291-297.

10. Bath M. Regulation of preparation courses for the Situational Judgement Test. Med Teach. 2016; 38(7):752.

11. Peak AS, Sheehan AH, Arnett S. Perceived utility of pharmacy licensure examination preparation tools. Am J Pharm Educ. 2006;70(2):Article 25.

12. McGaghie WC, Downing SM, and Kubilius R. What is the impact of commercial test preparation courses on medical examination performance?. Teach Learn Med. 2004;16(2):202-211.

13. Waskiewicz RA. Pharmacy students' test-taking motivation-effort on a low-stakes standardized test. Am J Pharm Ed. 2011;75(3): Article 41.

14. Gortney J, Rudolph MJ, Augstine JM, et al. National trends in the adoption of Pharmacy Curriculum Outcomes Assessment for student assessment and remediation. Am J Pharm Educ. 2019;83(6): Article 6796.

15. American Association of Colleges of Pharmacy (AACP). Academic Pharmacy's Vital Statistics. Available at https://www.aacp.org/article/academic-pharmacys-vital-statistics. Accessed September 20, 2021.

16. American Associaton of Colleges of Pharmacy (AACP). Fall 2020 Enrollments - Profile of Pharmacy Students. Available at: https://www.aacp.org/research/institutional-research/student-applications-enrollments-and-degreesconferred. Accessed September 20, 2021. 
Table 1. Participating Programs' Institutional Characteristics

Participating Programs (n [\%], N=58)+

\begin{tabular}{lc}
\hline Geographic Location & $12(20.7)$ \\
Northeast & $14(24.1)$ \\
South & $20(34.5)$ \\
Midwest & $12(20.7)$ \\
West & \\
Institution Type & $30(51.7)$ \\
Private & $28(48.3)$ \\
Public & \\
Typical Graduating Class Size (Student No.) & $5(8.6)$ \\
50 or less & $13(22.4)$ \\
51 to 75 & $11(19.0)$ \\
76 to 100 & $11(19.0)$ \\
101 to 150 & $7(12.1)$ \\
151 to 200 & $5(8.6)$ \\
More than 200 & \\
Number of Graduated Classes & $6(10.3)$ \\
0 to 5 & $7(12.1)$ \\
6 to 15 & $10(17.2)$ \\
16 to 25 & $1(1.7)$ \\
26 to 50 & $28(48.3)$ \\
More than 50 &
\end{tabular}

+ Percentages may not add up to $100 \%$ due to missing responses

Table 2. Bivariate Association Analyses between the 2019 NAPLEX First-attempt Pass Rates and PharmD Program Characteristics

\begin{tabular}{|c|c|c|c|}
\hline & NAPLEX Mean Passing Rate (SD) & $r^{*}$ & $p$ value \\
\hline \multicolumn{4}{|c|}{ Offer a NAPLEX Prep Program } \\
\hline Yes $(n=49)$ & $87.8(8.0)$ & 0.211 & .115 \\
\hline No $(n=8)$ & $92.5(5.8)$ & & \\
\hline \multicolumn{4}{|c|}{ Require the Prep Program for Every Student } \\
\hline Yes $(n=31)$ & $85.5(7.7)$ & 0.300 & .048 \\
\hline No $(n=13)$ & 90.7 (7.9) & & \\
\hline \multicolumn{4}{|c|}{ Use the Pre-NAPLEX Exam } \\
\hline Yes $(n=15)$ & $85.1(7.7)$ & 0.191 & .208 \\
\hline No $(n=30)$ & $88.3(8.2)$ & & \\
\hline \multicolumn{4}{|c|}{ Use a Third-party Resource } \\
\hline Yes $(n=35)$ & $85.6(8.2)$ & 0.379 & .010 \\
\hline No $(n=10)$ & $92.9(4.5)$ & & \\
\hline \multicolumn{4}{|c|}{ Use a "Home-grown" NAPLEX Prep Program } \\
\hline Yes $(n=18)$ & $89.5(6.5)$ & -0.237 & .118 \\
\hline No $(n=27)$ & $85.7(8.7)$ & & \\
\hline \multicolumn{4}{|l|}{ School Type } \\
\hline Public $(n=28)$ & $92.2(4.5)$ & -0.468 & $<.001$ \\
\hline Private $(n=29)$ & $84.9(8.8)$ & & \\
\hline \multicolumn{4}{|c|}{ Number of Classes the Program Has Graduated } \\
\hline 0 to $5(\mathrm{n}=5)$ & $81.7(9.8)$ & & \\
\hline 6 to $10(n=7)$ & $81.7(10.0)$ & & \\
\hline 11 to $25(\mathrm{n}=10)$ & $85.6(9.2)$ & 0.476 & $<.001$ \\
\hline 26 to $50(n=1)$ & $91.4(\mathrm{~N} / \mathrm{A})$ & & \\
\hline More than $50(\mathrm{n}=28)$ & $91.0(4.9)$ & & \\
\hline
\end{tabular}


Number of Students in Each Class

0 to $50(\mathrm{n}=4)$

$86.5(8.2)$

51 to $75(\mathrm{n}=13)$

76 to $100(\mathrm{n}=11)$

$85.7(10.6)$

$88.2(7.3)$

$91.6(4.2)$

101 to $150(\mathrm{n}=11)$

$90.0(7.4)$

151 to $200(n=7)$

$81.6(6.4)$

*Point-biserial correlation analysis was used to determine significance except for number of classes the program has graduated and number of students in each class for which Spearman correlation analysis was used to determine significance; significance was determined at $p<.05$

$\mathrm{SD}=$ standard deviation; $r=$ association coefficient

Table 3. Linear Regression of 2019 NAPLEX First-attempt Pass Rates on PharmD Demographic Characteristics

\begin{tabular}{|c|c|c|c|c|}
\hline & $\mathrm{B}[\mathbf{C I}]$ & SE & Beta & $p$ value* \\
\hline $\begin{array}{l}\text { Offer a NAPLEX Prep Program } \\
\quad(\text { Reference group }=\text { No) }\end{array}$ & $-0.641[-7.242-5.960]$ & 3.279 & -0.026 & .846 \\
\hline $\begin{array}{l}\text { School Type } \\
\quad \text { (Reference group=Private) }\end{array}$ & & 2.516 & -0.269 & .096 \\
\hline Number of Classes the Program Has Graduated & $2.361[0.495-4.227]$ & 0.927 & 0.435 & .014 \\
\hline Number of Students in Each Class & $-0.580[-2.361-1.202]$ & 0.885 & -0.105 & .516 \\
\hline
\end{tabular}

*Significance determined at $p<.05$

$\mathrm{B}=$ unstandardized coefficients; $\mathrm{CI}=95 \%$ confidence intervals; $\mathrm{SE}=$ standard error; Beta $=$ standardized coefficient

Table 4. Linear Regression of 2019 NAPLEX First-attempt Pass Rates on Various Aspects of the NAPLEX Preparation Programs and PharmD Program Characteristics

\begin{tabular}{|c|c|c|c|c|}
\hline & $\mathbf{B}[\mathbf{C I}]$ & SE & Beta & $p$ value* \\
\hline $\begin{array}{l}\text { Require the Prep Program for Every Student } \\
\text { (Reference group=No) }\end{array}$ & $0.018[-5.473-5.510]$ & 2.708 & 0.001 & .995 \\
\hline $\begin{array}{l}\text { Use the Pre-NAPLEX Exam } \\
\text { (Reference group=No) }\end{array}$ & $3.525[-1.578-8.629]$ & 2.516 & 0.211 & .170 \\
\hline $\begin{array}{l}\text { Use a Third-party Resource } \\
\text { (Reference group }=\text { No) }\end{array}$ & $1.101[-6.036-8.238]$ & 3.519 & 0.058 & .756 \\
\hline $\begin{array}{l}\text { Use a "Home-grown" NAPLEX Prep Program } \\
\text { (Reference group=No) }\end{array}$ & $-0.910[-5.774-3.954]$ & 2.398 & -0.056 & .707 \\
\hline $\begin{array}{l}\text { Public or Private } \\
\text { (Reference group=Private) }\end{array}$ & $-3.571[-9.849-2.706]$ & 3.095 & -0.222 & .256 \\
\hline Number of Classes the Program Has Graduated & $2.365[0.329-4.401]$ & 1.004 & 0.446 & .024 \\
\hline Number of Students in Each Class & $-0.415[-2.354-1.524]$ & 0.956 & -0.076 & .667 \\
\hline
\end{tabular}

* Significance determined at $p<.05$

$\mathrm{B}=$ unstandardized coefficients; $\mathrm{CI}=95 \%$ confidence intervals; $\mathrm{SE}=$ standard error; $\mathrm{Beta}=$ standardized coefficient 